\title{
Reseña del libro: Prendes, M. P. y Román, M. (Coords.) (2017). Entornos personales de aprendizaje. Una visión actual de cómo aprender con tecnologías. Barcelona: Octaedro
}

\author{
Victoria I. Marín Juarros \\ Carl von Ossietzky Universität Oldenburg (Alemania) \\ victoria.marin@uni-oldenburg.de
}

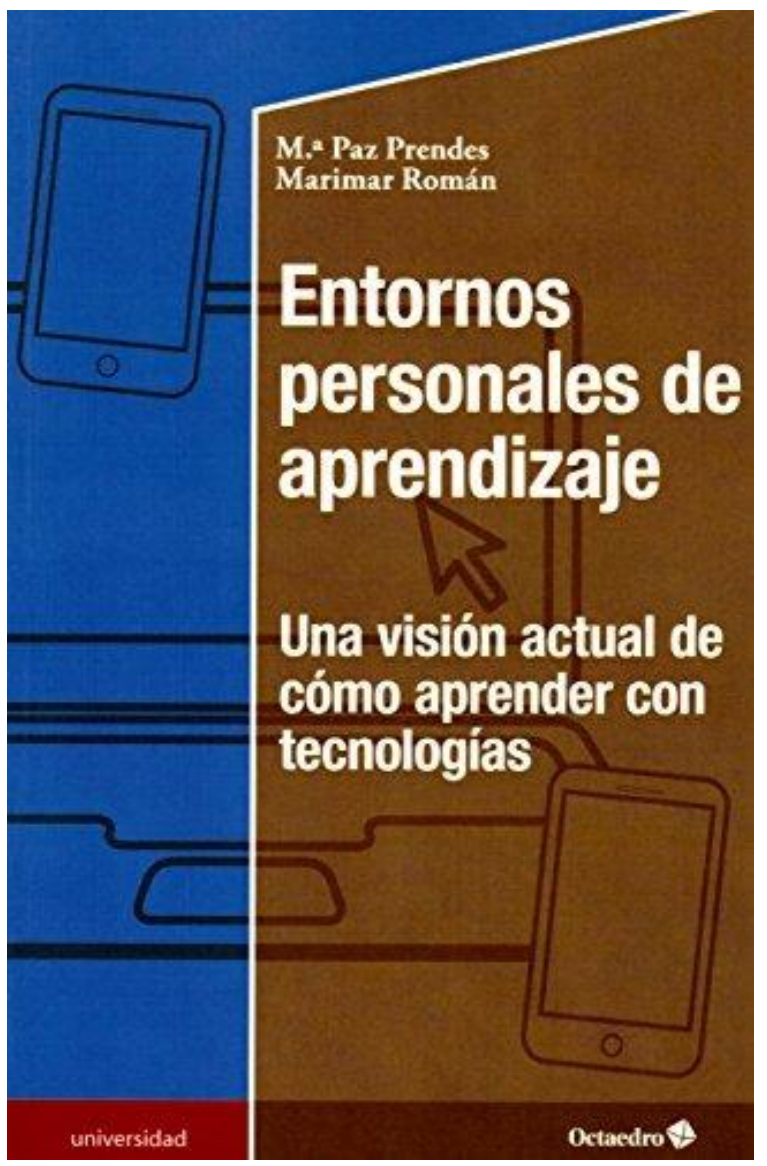

En la última década se ha oído hablar y discutir mucho sobre los Entornos personales de aprendizaje (por sus siglas en inglés, PLE), pero afortunadamente las conversaciones no se quedan en conceptos o herramientas, sino que llegan a discutir cómo aprendemos en el momento actual empleando tecnologías en diversos contextos. En ese sentido, y superando la conceptualización y discusión sobre el término, el libro Entornos personales de aprendizaje. Una visión actual de cómo aprender con tecnologías ofrece una mirada amplia de los PLE que abarca en su primera parte los resultados y la discusión de un proyecto de gran envergadura liderado por la Universidad de Murcia llevado a cabo entre 2013 y 2016 (CAPPLE), al mismo tiempo que aporta diferentes reflexiones derivadas de otros proyectos y estudios sobre PLE y otras miradas en su segunda parte.

La primera parte del libro inicia recordando los orígenes de la concepción de PLE, retomando las teorías de la psicología con el clásico The science of learning and the art of teaching de Skinner (1954), lo que nos hace volver a reflexionar sobre el elemento central, que es siempre el aprendizaje, como construcción personal y social, poniendo en juego las ideas del constructivimo y el conectivismo. Tras este comienzo, las autoras nos presentan el proyecto CAPPLE a rasgos generales, como el primer estudio empírico científico y de mayor relevancia en España, que explora el PLE de los/as estudiantes universitarios de último año de todas las ramas en diferentes universidades del país a partir de un cuestionario que considera 4 dimensiones derivadas de la literatura (autopercepción, gestión del aprendizaje, gestión de la información y comunicación).

A lo largo de los diferentes capítulos que componen esta primera parte del libro, se resume la fundamentación teórica de los PLE y las diferentes líneas de investigación en los últimos 5 años 
(segundo capítulo); se describe el procedimiento seguido en CAPPLE y el proceso de triple validación del cuestionario empleado, así como los logros derivados (tercer capítulo); y se presentan los resultados obtenidos a partir del cuestionario a modo de síntesis de acuerdo con cada dimensión, tras los cuales se proponen mejoras de respuesta institucional con el objetivo de ir más allá de mostrar los resultados y poner un granito de arena hacia el impacto positivo para poder generar cambios positivos en la educación superior en España (cuarto capítulo).

En conjunto, esta mitad de la lectura deja constancia de una serie de logros obtenidos por el proyecto, de gran interés tanto para investigadores/as de tecnología educativa (p.ej., la generación de una base de datos amplia de casos, la generación del modelo CAPPLE o la creación de un diagramador) como para el profesorado universitario, personas con cargos de autoridad educativa universitaria, o simplemente individuos interesados en saber un poco más sobre cómo se aprende en las universidades españolas con tecnologías (p.ej., la fotografía de los PLE de los universitarios/as españoles/as, sugerencias internacionales o propuestas de mejora de la formación dirigida al profesorado y alumnado, de integración de herramientas TIC en las universidades, de mejora de los procesos de enseñanza-aprendizaje o de mejora de las tareas de coordinación docente).

La segunda parte del libro incluye diversas visiones en torno al PLE, algunas de ellas derivadas de proyectos financiados a nivel estatal. Los/as diferentes autores/as hacen un recorrido por los conceptos o herramientas vinculados a los PLE. En el capítulo 5, se mencionan las plataformas de gestión del aprendizaje (por sus siglas en inglés, LMS), exploradas en la Universidad de las Islas Baleares en diversos proyectos con el objetivo de abrir paso a los PLE en la institución educativa. A continuación, en el capítulo 6, se aborda el estado de la formación de profesorado de enseñanza superior, incidiendo en la necesidad de romper inercias institucionales y generar modelos de formación didáctica para el uso de las TIC en el aula por parte de los profesores de cara a las demandas profesionales y sociales del siglo XXI. En el siguiente capítulo, se presenta la herramienta Carpeta digital derivado de un proyecto de la Universidad de Barcelona, como sistema de e-Portfolio, que incorpora elementos del PLE.

Finalmente, el capítulo 8 incorpora unas reflexiones finales alrededor del PLE y su futuro, que abren la puerta al diálogo, pero también a múltiples interrogantes y líneas nuevas de investigación, que pueden seguir siendo exploradas por investigadores/as interesados en el tema.

Se abarcan, pues, desde consideraciones presentes, que nos invitan a ver los PLE como un proceso de aprendizaje parcialmente no intencional, pero que requiere apoyo estructurado, sobre todo para su desarrollo. También nos hacen pensar que debemos dejar de dar por supuesto que los/as estudiantes sean competentes digitalmente a la hora de aprender y que el papel del profesorado es clave en la aportación de recursos y estrategias para que los aprendices puedan autorregular su aprendizaje y recibir apoyo en ese crecimiento de su PLE en la universidad y, especialmente, en su vida más allá del ámbito académico. Otras visiones apuntan hacia el futuro, vislumbrando en el horizonte bots asistentes, el uso en alza de las analíticas del aprendizaje para la personalización del aprendizaje (learning analytics), así como un mayor aprovechamiento de los cursos masivos abiertos en línea (más conocidos por sus siglas en inglés, MOOC), de los recursos educativos abiertos (REA), del software social o del aprendizaje informal y móvil.

Como conclusión, se trata de una lectura altamente recomendada tanto para investigadores/as en sus diferentes fases en el ámbito del aprendizaje con tecnologías, como profesores/as universitarios/as interesados/as en conocer más sobre los PLE, su contexto, ejemplos y resultados, en el ámbito de la educación superior. 